\title{
Why the Negation Problem Is Not a Problem for Expressivism*
}

\author{
Jeremy Schwartz \\ Texas Tech University
}

\author{
Christopher Hom \\ Texas Tech University
}

February 22, 2014

\section{Introduction}

In 1999, Unwin introduced a puzzle about expressivism and negation. He showed that existing accounts of expressivism cannot accommodate even the simplest case of negated normative judgments involving the permissible, the required, and the forbidden. Since descriptivist accounts of normative language do not have a problem accommodating these cases, Unwin believed that the problem was a problem specifically for expressivists. While some theorists have held that it is the negation operator that gives rise to Unwin's puzzle ${ }^{1}$ most have agreed with Unwin's original diagnosis that the problem arises for expressivism generally. ${ }^{2}$ Accordingly, the changes that have been proposed to accommodate this problem have been changes to the very structure of expressivism.

Although we agree with Unwin that classical expressivism cannot accommodate these central cases, we disagree with both Unwin and his critics about where to place the blame. Rather than blaming expressivism as such or the interaction between expressivism and the negation operator, we argue that Unwin's problem (hereafter, the Negation Problem) arises from an interaction between expressivism and the kinds of normative examples on which it has usually focused. Since the problem only besets a particular, but central, case for expressivism, the solution will be to add structure to accommodate these cases rather than revise its existing structure. To support this claim, we will argue for three theses. 1) A problem that is structurally identical to the Negation Problem arises in non-normative cases, and this problem is solved once the hidden quantificational structure involved in such cases is uncovered. 2) The terms 'required', 'permissible', and 'forbidden' can also be analyzed in terms of hidden quantificational structure, and the Negation Problem disappears once this

\footnotetext{
*Forthcoming, Noûs. Penultimate draft - please do not cite.

${ }^{1}$ Horgan \& Timmons 2009.

${ }^{2}$ Unwin 1999, Schroeder 2008a.
} 
hidden structure is uncovered. 3) The Negation Problem does not arise for normative language that has no hidden quantificational structure. In fact, we argue that in certain contexts, 'good' is such a primitive normative term that avoids the Negation Problem. We conclude that the Negation Problem is not really a problem about expressivism at all but is rather a feature of the quantificational structure of the required, permitted, and forbidden.

These claims are argued for in five sections. In the first section, we explain the Negation Problem, distinguish it from the original Frege-Geach problem which was about embedding, and explain how our own view carves up the logical space in a different way than is usual. In sections two through four, we explicitly defend each of the main theses in the previous paragraph. Finally, in the fifth section we compare our account to a rival account of this phenomenon given by Mark Schroeder. We show that our account does a better job of explaining how the required, permissible, and forbidden can satisfy the internalism requirement. We conclude that although Schroeder is right to demand more structure from expressivism, the additional structure should be inserted as a quantificational modifier rather than as an activity that is interposed between our attitude and its primary object.

\section{Two Problems for Negation}

The Frege-Geach problem originally arose for non-cognitivists because of embedded contexts. According to Geach 1965, for example, the problem lay in thinking that the meaning of a term could be tied to some "performance" of the speaker (Geach 1965: 461). Consider, for example, Ayer's account where the meaning of the sentence, 'cheating is wrong' was tied to the speaker "evincing... disapproval" (Ayer 1936: 158). ${ }^{3}$ The problem is that in most embedded contexts, the speaker may have some attitude or other toward the whole sentence but does not seem to disapprove of the sentence that has been embedded. Thus, when someone says that 'if cheating is wrong then assisting others in cheating is wrong' they evince no disapproval towards either cheating or assisting others in cheating. But then, pace Ayer's emotive definition of the sentence 'cheating is wrong', there are instances where 'wrong' is applied meaningfully to 'cheating' without the speaker evincing disapproval of cheating. In short, the Frege-Geach problem originally asked how the meaning of a term could depend on the performance or attitude of a speaker when there were contexts in which this term appeared without the accompanying performance or attitude. Since expressivists agree with their non-cognitivist ancestors that the meaning of the term is tied to the attitude of the speaker, this problem of embedded contexts arises for them just as forcefully as it did for earlier non-cognitivists. Since non-

\footnotetext{
${ }^{3}$ Ayer's full quotation is: "In adding that this action is wrong I am not making any further statement about it. I am simply evincing my moral disapproval of it. It is as if I had said, 'You stole that money,' in a peculiar tone of horror, or written it with the addition of some special exclamation marks" (Ayer 1936: 158). We have omitted the 'moral' from 'moral disapproval' because that needlessly invites the objection of circularity.
} 
cognitivists and expressivists agree on this point, we somewhat anachronistically refer to the whole movement that includes Ayer, Stevenson, Hare, Blackburn, and Gibbard as expressivism. ${ }^{4}$

As was understood right from the start, negation is one of these embedded contexts. To evince disapproval of not cheating does not evince anything at all towards cheating. It follows that any non-cognitivist or expressivist solution to the problem of embedded contexts must also thereby offer an account of negated contexts. As a special case of the original embedding problem, negated contexts are therefore intimately connected to solutions to the Frege-Geach problem and may have specific problems that arise only for the case of negation.

Unwin 1999 has argued that negation reveals specific problems and that these problems turn out to be serious enough to threaten the entire expressivist project. The problem is that for a given moral sentence there are three ways to negate it, of which an expressivist can only account for two. Consider the following four sentences:

(S) Sally thinks that giving to charity is required.

(n1) Sally does not think that giving to charity is required.

(n2) Sally thinks that giving to charity is not required.

(n3) Sally thinks that not giving to charity is required.

In (n1), Sally need not adopt any attitude toward charity, whereas in (n2) she holds that not giving to charity is permitted, and in (n3) she holds that charity is forbidden. The (n1) negation is the broadest negation. Its content is consistent with three options: a) Sally has no attitudes about giving to charity (e.g. she hasn't thought about it, is indifferent or agnostic toward it, isn't conscious, etc.); b) Sally has an attitude toward giving to charity that falls short of moral approval, but does not amount to moral disapproval either; c) Sally has an attitude of moral disapproval toward giving to charity. The (n3) negation is the narrowest negation as its content is only consistent with option c; i.e. that Sally morally disapproves of giving to charity. In the (n2) case, Sally thinks that not giving to charity is permitted. Thus her attitude toward charity must fall short of moral approval, but it is also possible that she morally disapproves of giving to charity altogether. In other words, $(\mathrm{n} 2)$ is consistent with either option b or c. That (n2) is consistent with option b or c means that (n1), (n2), and (n3) are ordered by the relation of proper containment. Every option consistent with (n3) is consistent with (n2), but not vice versa, and every option consistent with (n2) is consistent with (n1), but not vice versa. Call this relation that holds between the contents of (n1) - (n3) the Concentric Structure for Negation.

The Concentric Structure for Negation arises in part because of the threevalued nature of our moral vocabulary. Unwin's account assumes that the required is different from both the forbidden and the permitted. In other words, it is because (n2) negates the predicate but does not affirm the contrary of the

\footnotetext{
${ }^{4}$ For a similar use of 'expressivism' to apply to the whole non-descriptivist movement, see Smith 1994: chapter 1.
} 
predicate that there is such a concentric structure. Imagine a hard-core maximizing utilitarian who believes that an action is required if it maximizes welfare and forbidden if it does not. Anything that is not required is forbidden, and (n2) collapses into (n3). Since such a utilitarian does not believe that any acts are merely permissible, the Negation Problem will not arise. Of course, denying the existence of the permissible is a steep cost. We point this out to show that the Concentric Structure for Negation depends upon our normative vocabulary being three-valued instead of two-valued.

Now consider an expressivist's attempt to analyze these sentences.

$$
\begin{aligned}
& \text { (S) = Sally hoorays! giving to charity. } \\
& \text { (n1) = Sally does not hooray! giving to charity. } \\
& \text { (n2) = ???? } \\
& \text { (n3) = Sally hoorays! not giving to charity. }
\end{aligned}
$$

Expressivists can capture (n1) by negating Sally's expression of approval, and they can capture (n3) by saying that Sally expresses approval of the opposite of charity. But just what is Sally expressing when she says that not giving to charity is permitted?

The problem, as Schroeder 2008a emphasizes, is that expressivists simply don't have enough logical structure to handle all the different types of negation that are possible. ${ }^{5}$ In the original sentence, one can place a negation in front of the 'thinks', 'giving to charity', and 'required', but since expressivists try to analyze 'thinks required' into one act of approving they lose a place to insert a negation sign. In fact, the slot that they lose is the one that would be placed in front of 'required'. This is a deep problem for expressivists because the fact that 'required' can be negated makes it seem like 'required' behaves like a predicate rather than something that is expressed through the sentence. Now it is open to an expressivist to postulate further structure. One way to do this is to postulate two distinct attitudes (say disapproving and tolerating) ${ }^{6}$ claim that they are incompatible with each other, and then define 'charity is required' in terms of disapproving of not giving to charity and 'charity is not required' in terms of tolerating not giving to charity. But, as Unwin points out (Unwin 1999: 342) and as Schroeder forcefully brings home (2008a: 580-581), such a move does not explain how disapproving and tolerating are logically incompatible with each other. It simply postulates that they are incompatible without explaining in what this inconsistency consists.

The problem can also helpfully be put in terms of external negation. In (n1), the entire sentence is negated and in (n3), the content internal to the attitude is negated. Sentential and internal negation pose no special problems for expressivism. However, the disagreement between (n2) and (S) is explained by neither

\footnotetext{
${ }^{5}$ Schroeder 2008a: 590. "If the problem arises because the expressivists account has insufficient structure, there is only one solution: to give the expressivists account sufficient structure."

${ }^{6}$ See Blackburn 1988: 511-512.
} 
sentential nor internal negation. Intuitively, (n2) negates the attitude of disapproval itself not its content. The negation is thus external to the attitude. Since non-expressivists can explain (n2) as a negation of the predicate 'wrong', they don't need to appeal to external negation, and they worry about how external negation works differently from more familiar kinds of negation. ${ }^{7}$ If, at this point, an expressivist attempts to explain external negation by pointing to disapproval and tolerance as distinct attitudes that disagree, the non-expressivist calls foul. The non-expressivist accepts, of course, that disapproval and toleration are inconsistent states, they just don't believe that external negation is required to explain this fact. Non-expressivists will explain toleration in terms of ordinary content-disagreement about the predicate 'wrong'. Appealing to the attitudes of tolerance and disapproval, therefore, turns out to be no help at all. The question all along was how attitudes like disapproval and toleration can logically disagree. The non-expressivists have an account of this - they disagree because they are about contradictory contents. The expressivists have no corresponding explanation.

While some have seen the Negation Problem as a special case of the larger embedding problem - embedding as it applies to negation - Unwin himself, and Schroeder after him have argued that the Negation Problem generalizes to other logical connectives. Consider, the logical relation of conjunction as applied to the following two sentences, 'Sally thinks giving to charity is required' and 'Sally thinks paying higher taxes is required'.

$\left(\mathrm{S}_{\&}\right)$ Sally thinks giving to charity is required.

(\&1) Sally thinks giving to charity is required and Sally thinks paying higher taxes is required.

(\&2) Sally thinks giving to charity is required and paying higher taxes is required.

(\&3) Sally thinks giving to charity and paying higher taxes is required.

Notice that each of the three are different. (\&1) attributes to Sally two distinct mental states whereas (\&2) and (\&3) attribute to Sally a single mental state. (\&2) attributes to Sally a single mental state about two distinct moral requirements whereas (\&3) attributes to Sally a single mental state about a single, conjunctive moral requirement.

Again we can see that the expressivist has only two slots in which to insert the conjunction operator:

\footnotetext{
${ }^{7}$ Schroeder makes the same point in terms of A-type inconsistency and B-type inconsistency. A-type inconsistency is inconsistency that is explained because we have the same attitude toward inconsistent states. B-type inconsistency is any other type of inconsistency. The attitudes of believing and planning are both capable of A-type inconsistency. A belief and a plan disagree by taking the same attitude toward inconsistent contents. In fact, Schroeder argues, A-type inconsistencies are the only kind of inconsistencies that we understand. Since expressivists assume that disapproval of stealing and toleration of stealing are inconsistent states despite having identical contents, they rely upon the more mysterious B-type inconsistency. They owe us an explanation for how that could work.
} 
$\left(\mathrm{S}_{\&}\right)$ Sally approves of giving to charity.

(\&1) Sally approves of giving to charity and Sally approves of paying higher taxes.

(\&2) ????

(\&3) Sally approves of giving to charity and paying higher taxes.

Expressivists have lost logical structure and again expressivism seems to be to blame. If this generalization of the Negation Problem is correct, then Horgan and Timmons (2009: 92), for example, are wrong to think of the Negation Problem as arising from the special features of negation. Instead, it will arise for other logical operators. Once negation has been cleared of all the blame, it seems that the only option left is to conclude that the Negation Problem applies not just to expressivist accounts of negation but to expressivist accounts of embedding generally.

Although we believe that Schroeder and Unwin were right to clear the negation operator of all the blame, they were wrong to conclude that expressivism itself is therefore the culprit. In fact, we will pin the Negation Problem on a completely overlooked suspect - the specific normative vocabulary on which expressivists have usually focused. In the next section, we will show that the Concentric Structure for Negation arises in ordinary descriptive language where there is hidden quantification. In the section after that, we suggest a solution to the Negation Problem which postulates hidden quantification for the required, permissible, and forbidden.

\section{The "Negation Problem" without Expressivism}

Consider some non-expressivist cases that exhibit the Concentric Structure for Negation. That such a similar structure occurs for even non-expressive language suggests that expressivism is not the cause of this structure. Consider the following sentences:

Group A

1. Sally loves playing tennis.

2. Sally hates eating anchovies.

3. Sally is a misanthrope.

4. Sally is an omniarch.

Each of the sentences above does not require an expressivist analysis. Now consider the possible negations for the first example:

$\left(\mathrm{n} 1_{1}\right)$ Sally doesn't love playing tennis.

$\left(\mathrm{n} 2_{1}\right)$ Sally doesn't love playing tennis.

$\left(\mathrm{n} 3_{1}\right)$ Sally loves not playing tennis. 
While $\left(\mathrm{n} 1_{1}\right)$ and $\left(\mathrm{n} 3_{1}\right)$ are fairly straightforward, $\left(\mathrm{n} 2_{1}\right)$ requires explanation. By putting focus on the verb 'love' the speaker is exploiting the asserted content to pragmatically implicate either that Sally has a positive attitude toward playing tennis which falls short of loving it, or else that loving is completely the wrong attitude because she actually holds the opposite. Our reading is supported by the felicity of each of the following supplementary statements:

(n2 $2_{1 b}$ Sally doesn't love playing tennis. [She merely likes it.]

(n21c) Sally doesn't love playing tennis. [She actually dislikes it.]

If this focus reading is plausible, then there are three natural ways of negating sentence (1). The $\left(n 1_{1}\right)$ negation is the broadest negation and its content is consistent with three options: a) Sally has no attitudes about playing tennis (e.g. she hasn't thought about it, doesn't know what it is, isn't conscious, etc.); b) Sally has positive attitudes toward playing tennis that fall short of loving; c) Sally dislikes playing tennis. The $\left(\mathrm{n} 3_{1}\right)$ negation is the narrowest negation and its content is only consistent with option c; i.e. that Sally dislikes playing tennis. Whereas the $\left(\mathrm{n} 2_{1}\right)$ negation, as we have seen, expresses intermediary content that falls between the $\left(\mathrm{n} 1_{1}\right)$ and the $\left(\mathrm{n} 3_{1}\right)$ negations by being consistent with either option b or option c. Because every option for $\left(\mathrm{n} 3_{1}\right)$ is properly contained in $\left(\mathrm{n} 2_{1}\right)$, and similarly every option for $\left(\mathrm{n} 2_{1}\right)$ is properly contained in $\left(\mathrm{n} 1_{1}\right)$, this just is the Concentric Structure for Negation. ${ }^{8}$

A parallel Concentric Structure for Negation holds for sentences (2)-(4) as their (n2) negations can be expressed as follows:

$\left(\mathrm{n} 2_{2 \mathrm{~b}}\right)$ Sally doesn't hate eating anchovies. [She merely dislikes them.]

$\left(\mathrm{n} 2_{2 \mathrm{c}}\right)$ Sally doesn't hate eating anchovies. [She actually likes them.]

(n2 $\left.2_{3 \mathrm{~b}}\right)$ Sally isn’t a misanthrope. [She only hates some people.]

$\left(\mathrm{n} 2_{3 \mathrm{c}}\right)$ Sally isn't a misanthrope. [She likes everyone.]

(n2 $2_{4}$ ) Sally isn't an omniarch. [She only rules some people.]

$\left(\mathrm{n} 2_{4 \mathrm{c}}\right)$ Sally isn't an omniarch. [She rules no one.]

The crucial point is that in all of these (n2) cases, there is a particular focus reading that is bifurcated between being either slightly too strong on the salient scale or quantity, or else radically incongruent with the facts. Together

\footnotetext{
${ }^{8}$ There is a worry here that loving, unlike approving, is not a content-negating attitude. For example, the thought is that while Sally may like not playing tennis, she may also like playing tennis; i.e. she may like everything. If this were the case, then (n3) and (S) would no longer contradict each other. However, on the account we will soon develop, loving is liking everything about. It would then at least seem odd to say that Sally who likes everything about playing tennis is not in disagreement with John who likes everything about not playing tennis. Plausibly, therefore, loving is a content negating attitude. At the very least, we have shown that such a non-expressivist analogy is plausible, and it is up to our opponent to explain why there couldn't be such a content negating attitude in the non-expressive realm. Thanks to Jacob Beck for raising this worry.
} 
with their corresponding (n1) and (n3)'s, each set instantiates the Concentric Structure for Negation.

These cases contrast with negations that do not exhibit the Concentric Structure for Negation. For example, consider the following sentences that have the same grammatical form as the examples above:

\section{Group B}

5. Sally remembers playing tennis.

6. Sally talks about eating anchovies.

7. Sally is a crank.

8. Sally is a senator.

Consider the possible negations for the first example of Group B:

$\left(\mathrm{n}_{5}\right)$ Sally doesn't remember playing tennis.

(n2 $\left.2_{5}\right)$ ????

(n3 $3_{5}$ Sally remembers not playing tennis.

$\left(n 1_{5}\right)$ is fine (e.g. Sally isn't a conscious being with memories). (n35) is fine (e.g. Sally remembers declining playing tennis to go swimming instead). The distinction from the first set of cases comes in attempting to isolate an (n2 $\left.2_{5}\right)$ reading that arises from placing focus on the verb (i.e. Sally doesn't remember playing tennis). Certainly we can think of contexts whereby hearers can reasonably infer to some conversationally implicated content or other upon hearing the focused reading of $\left(\mathrm{n} 2_{5}\right)$ (e.g. Sally merely imagined playing tennis, Sally was hypnotized into falsely thinking she had played tennis, etc.). But the crucial point is that the Group B (n2) cases are distinguished from the Group A (n2) cases in that they are not regimented to naturally offer up the bifurcated (n2) analogues, and hence they fail to generate the Concentric Structure for Negation.

A puzzle naturally arises: what does 'loves' or 'is a misanthrope' have in common with the other predicates in Group A that they fail to have in common with the predicates in Group B (e.g. 'remembers', 'is a crank') such that the more regimented (n2) readings arise? Our hypothesis for explaining the regimented nature of the bifurcated (n2) readings is that certain words have hidden quantification as part of their lexical structure. ${ }^{9}$ Consider sentence (1) about Sally loving playing tennis. While one understanding of this is that Sally strongly likes playing tennis, there is another understanding where Sally likes everything about playing tennis - e.g. she likes serving, playing in tournaments, its association with the Duchess of Kent, etc. This latter understanding of loving has historical precedence in Plato's Republic, ${ }^{10}$ and it helps make perfectly

\footnotetext{
${ }^{9}$ The suggestion is far from radical given the quantificational analyses of such phrases as definite descriptions (Russell 1905, 1919), action verbs (Davidson 1967), modal terms (Kratzer 1991), and complex demonstratives (King 2001).

10 “... it's not proper for an erotic man to forget that all boys in the bloom of youth in one way or another put their sting in an erotic lover of boys and arouse him; all seem worthy of
} 
explicit the hidden quantification that provides a clear solution to the problematic (n2) cases. ${ }^{11}$ By analyzing genuine loving of $x$ as liking everything about $x$, or liking $x$ in all ways, the meaning of the (n2) negation becomes clear:

$\left(\mathrm{S}_{1}{ }^{\prime}\right)$ Sally likes playing tennis in all ways.

$\left(\mathrm{n} 1_{1}^{\prime}\right)$ It's not the case that Sally likes playing tennis in all ways.

$\left(\mathrm{n} 2_{1}^{\prime}\right)$ Sally likes playing tennis not in all ways.

$\left(\mathrm{n} 3_{1}{ }^{\prime}\right)$ Sally likes not playing tennis in all ways.

The quantificational analysis of $\left(\mathrm{n} 2{ }_{1}{ }^{\prime}\right)$ captures what we want (i.e. the negation modifies the content of the claim on some quantitative scale that is consistent with either the option b or option c readings):

$\left(\mathrm{n} 2{ }_{1 \mathrm{~b}}{ }^{\prime}\right)$ Sally likes playing tennis not in all ways. [She merely likes it in some ways.]

$\left(\mathrm{n} 2_{1 \mathrm{c}}{ }^{\prime}\right)$ Sally likes playing tennis not in all ways. [She actually likes playing tennis in no way.]

The hidden quantificational analysis generalizes to the bifurcated (n2) readings of sentences 2-4:

$\left(\mathrm{n} 2_{2 \mathrm{~b}}{ }^{\prime}\right)$ Sally dislikes eating anchovies not in all ways. [She merely dislikes it in some ways.]

$\left(\mathrm{n} 2 \mathrm{2c}^{\prime}\right)$ Sally dislikes eating anchovies not in all ways. [She actually likes eating them in all ways.]

$\left(\mathrm{n} 2_{3 \mathrm{~b}}{ }^{\prime}\right)$ Sally hates not all people. [She only hates some of them.]

$\left(\mathrm{n} 2_{3 \mathrm{c}}{ }^{\prime}\right)$ Sally hates not all people. [She actually likes all of them.]

$\left(\mathrm{n} 2_{4 \mathrm{~b}}{ }^{\prime}\right)$ Sally rules not all people. [She only rules some of them.]

$\left(\mathrm{n} 2{ }_{4 \mathrm{c}}{ }^{\prime}\right)$ Sally rules not all people. [She actually doesn't rule anyone.]

To summarize, we have demonstrated that there is an analogue to the Negation Problem wherever the Concentric Structure for Negation occurs in nonnormative sentences like those in Group A involving predicates such as 'loves' and 'is a misanthrope'. Once their hidden quantificational structure is made explicit, the problem is solved. Not only does it make available additional structure

attention and delight. Or don't you people behave that way with the fair? You praise the boy with a snub nose by calling him 'cute'; the hook-nose of another you say is 'kingly'; and the boy between these two is 'well proportioned'; the dark look 'manly'; and the white are 'children of gods.' And as for the 'honey-colored,' do you suppose their very name is the work of anyone other than a lover who renders sallowness endearing and easily puts up with it if it accompanies the bloom of youth? And, in a word, you people take advantage of every excuse and employ any expression so as to reject none of those who glow with the bloom of youth" (Plato, 474d-475a).

${ }^{11} \mathrm{We}$ set aside the adverbial analysis of loving as liking strongly because its (n2) negation (i.e. Sally likes not strongly playing tennis) is not consistent with the (n3) negation that Sally strongly likes not playing tennis. See Thomason and Stalnaker 1973: 209-210. 
for the requisite negation, but it does so in a way that preserves, in a unified way, the bifurcated reading of (n2) assertions. This suggests that hidden quantification embedded within the lexical meaning of the relevant predicate (e.g. 'is required') is a candidate for being a general solution to the Negation Problem that is independent of whether the sentence has an expressivist analysis. If this is a structural problem that arises generally (i.e. for certain non-expressivist cases where the predicate has hidden quantificational structure), then the Negation Problem is not essential to expressivist analyses of normative language. In the next section, we explore how the hidden quantificational analysis can be marshaled to explain the normative cases of the Negation Problem as well.

\section{The Quantificational Account}

Our hypothesis is that the correct solution to the Negation Problem falls out of more general considerations about hidden quantification in natural language which apply to both normative and non-normative language alike. On our view, moral language gets analyzed as a general two-valued normative attitude, say approval and disapproval, directed at a proposition quantified over the desires for which one approves of the actions. The additional quantificational structure is posited for the object of the attitude, and not for the structure of the attitude itself. ${ }^{12}$ To be required is to be approved of for any arrangement of desires. To be permissible is to be approved of for some arrangement of desires. To be forbidden is to be approved of for no arrangement of desires. For example, 'Sally thinks giving to charity is morally required for George' is analyzed as Sally approving of giving to charity no matter what George happens to desire. 'Sally thinks that charity is morally permitted for George' is analyzed as Sally approving of charity for some arrangement of George's desires. And 'Sally thinks that giving to charity is morally forbidden for George' is analyzed as Sally approving of giving to charity for no arrangement of George's desires. ${ }^{13}$

In the required case, we say that Sally unconditionally approves of George's giving to charity. In the permitted case, we say that Sally conditionally approves of George's giving to charity. In the forbidden case, we say that Sally unconditionally approves of George's not giving to charity. Although the language of conditional and unconditional is useful, it is important to guard against some misunderstandings suggested by these terms. The first misunderstanding is that unconditional approval implies approval of giving to charity in all contexts. In other words, to say charity is required would involve approving of giving to charity whether you are wealthy, poor, or heavily indebted, whether the charities are well-run or ill-managed. Our account has no such implications. To say something is morally required does not say that it is good in all contexts - it just

\footnotetext{
${ }^{12}$ This is especially important to note because we would otherwise face a problem analogous to the Frege-Geach problem but for embedding under quantified contexts. Thanks to our anonymous reviewer for pressing us to clarify these points.

${ }^{13}$ We have assumed that the primitive normative attitude is two-valued lest the Negation Problem arise for our primitive as well. We return to issues raised by this assumption in the next section.
} 
says that it is good no matter what we happen to want. In theory, Sally could approve only of giving to charity in this one context but do so unconditionally. This would mean that she thinks that in this context George ought to give no matter what he happens to want.

The second misunderstanding is that when Sally unconditionally approves of George's giving to charity, there are many acts of approval. For instance, she approves of it for George when he has a strong desire to give to charity, she approves of it when he has no desire, and she approves of it when he has a strong desire not to give to charity. In other words, unconditional approval makes it sound like the quantification is external to the attitude. One might worry that we have simply replaced external negation with external quantification (i.e. all of the ways in which she approves of it for George). It is important here to remember that our account holds that there is only one act of approval that has a quantified proposition as its content. Sally's act of approval already has all of George's possible desires as part of its object.

On our view, the hallmark of the morally obligatory (i.e. the morally required) is that it is a form of normative endorsement that applies to us regardless of what we happen to want. This understanding of the morally obligatory is hardly new. It traces its roots to Kant, continues to have influence on contemporary understandings of the morally obligatory, and provides an impetus for expressivism itself. ${ }^{14}$ It should be clear, therefore, that we are not arguing for a new understanding of the required, permitted, or forbidden. Instead, we argue that a traditional conception is naturally understood as involving hidden quantificational structure, and we show that if this conception of the obligatory is correct, the Negation Problem does not arise. ${ }^{15}$

\footnotetext{
${ }^{14}$ For a clear account of the relationship between this understanding of morality and expressivism see Smith 1994: 12.

${ }^{15} \mathrm{By}$ analyzing the required in terms of unconditional approval, we risk precluding the possibility of supererogatory actions. If all unconditionally approved acts are required, there seems to be no room for acts that are praiseworthy and admired, even unconditionally so, but not required. We may approve of a soldier throwing herself on a grenade for any arrangement of the soldier's desires without thinking that this action is required. In short, our analysis seems to defend and assume the traditional "threefold classification" (Urmson 1958: 198-9) which divides actions into the required, the permissible, and the forbidden. By perpetuating this threefold classification, we inherit its difficulties. A full discussion of this controversial topic is beyond the scope of this paper, but we offer the following brief remarks. First, the Negation Problem itself is an attack on the traditional distinction. Thus, the original charge against expressivism is that it fails even to distinguish the permissible from the forbidden, let alone the problematic cases of the supererogatory for which even non-expressivists have problems accounting. Solutions, ours included, have consequently focused on vindicating the traditional deontic categories. Second, the supererogatory itself requires explanation. As many have noted (Pybus 1982: 194, 1986:526-7, Raz 1975: 164, Attfield 1979: 488-9) the supererogatory flirts with paradox. Supererogatory acts are those that we have sufficient reason to admire but not sufficient reason to do. Can such a double standard even be upheld? Many solutions that avoid this paradox do so by acknowledging that supererogatory acts are, after all, required in a certain way. Thus, Baron 1987 tries to understand the supererogatory in terms of imperfect duties and even Urmson 1958: 214 finally understands the supererogatory to be duties that we can exact of ourselves but not exact of others. But if the supererogatory/required distinction turns out to be simply a division within the realm of the required, then we need only point out that our account gives an analysis of 'required' in the widest possible sense. There is
} 
Here is the application of our account to solve the Negation Problem:

(S) Sally thinks giving to charity is required.

$\left(\mathrm{S}^{\prime}\right)$ Sally approves of giving to charity unconditionally.

$\left(\mathrm{S}^{*}\right)$ APPROVE (Sally, $(\forall \mathrm{d})$ (giving to charity under d))

(n1) Sally doesn't think giving to charity is required.

(n1') Sally doesn't approve of giving to charity unconditionally.

$\left(\mathrm{n} 1^{*}\right)$ APPROVE (Sally, ( $\left.\forall \mathrm{d}\right)$ (giving to charity under d))

(n2) Sally thinks giving to charity is not required.

(n2') Sally approves of giving to charity not unconditionally.

$\left(\mathrm{n} 2^{*}\right)$ APPROVE (Sally, $\sim(\forall \mathrm{d})$ (giving to charity under d))

(n3) Sally thinks not giving to charity is required.

$\left(\mathrm{n} 3^{\prime}\right)$ Sally approves of not giving to charity unconditionally.

$\left(\mathrm{n}^{*}\right)$ APPROVE (Sally, $(\forall \mathrm{d})(\sim$ giving to charity under d))

It is important to point out how the analysis successfully captures the Concentric Structure for Negation. Recall that the three options for the negation of (S) are: a) Sally has no attitudes about giving to charity (e.g. she lacks the concept of charity, she has no conscious attitudes whatsoever, etc.; b) Sally thinks that not giving to charity is permissible but not required; c) Sally thinks that the opposite (i.e. not giving to charity) is actually required. Straightforwardly, the analysis gives us that the content of $(\mathrm{n} 1)$ is consistent with each of options a through $\mathrm{c}$, and that the content of (n3) is only consistent with option c. Crucially, the account generates content for (n2) that is intermediary between (n1) and (n3) which is consistent with either option b or option c. If Sally approves of giving to charity not under all conditions, then this is consistent with either her approving of not giving to charity under some conditions (option b), or her approving of not giving to charity under all conditions (option c).

To more clearly showcase the depth of our view and its theoretic consequences, we introduce the following notational terminology: ${ }^{16}$

$$
\begin{aligned}
& \mathrm{A} \square={ }_{\mathrm{df}} \text { unconditional approval (i.e. being morally required) } \\
& \mathrm{A} \diamond=_{\mathrm{df}} \text { conditional approval (i.e. being morally permitted) }
\end{aligned}
$$

This allows us to represent our solution to the Negation Problem more perspicuously:

then room to distinguish the supererogatory from the narrowly required within this broad understanding.

${ }^{16}$ Echoing standard notation from modal logic, we let ' $\square$ ' stand for quantification over all arrangements of desires, and ' $\vee$ ' stand for quantification over some arrangements of desires. 
(S) Sally thinks giving to charity is required.

( $\left.\mathrm{S}^{* *}\right) \mathrm{A} \square$ (giving to charity)

(n1) Sally doesn't think giving to charity is required.

$\left(\mathrm{n} 1^{* *}\right) \sim \mathrm{A} \square$ (giving to charity)

(n2) Sally thinks giving to charity is not required.

$\left(\mathrm{n} 2^{* *}\right) \mathrm{A}^{\sim} \square$ (giving to charity) $=\mathrm{A} \diamond^{\sim}$ (giving to charity)

(n3) Sally thinks not giving to charity is required.

$\left(\mathrm{n} 3^{* *}\right) \mathrm{A} \square($ giving to charity)

We are now in position to make four key observations about the theory. First, $\left(\mathrm{n} 2^{* *}\right)$ points out that the theory arrives at the right result by identifying the permissibility of not giving to charity with it not being required to give to charity. The result follows logically from the dual relation between the existential and the universal quantifier, and the fact that conditional and unconditional approval are defined relative to quantification over conditions. Hence our new operators share a dual relation: ${ }^{17}$

$\mathrm{A}^{\sim} \square(\mathrm{p})=\mathrm{A} \diamond^{\sim}(\mathrm{p})$

[i.e. not being morally required to do $\mathrm{p}=$ being permitted to not do $\mathrm{pl}$

$\mathrm{A}^{\sim} \diamond(\mathrm{p})=\mathrm{A} \square^{\sim}(\mathrm{p})$

[i.e. not being permitted to do $\mathrm{p}=$ being required to not do $\mathrm{p}$ ]

Second, the new notion makes explicit that our theory generates the content for (n2) without having to postulate a new form of negation that is external to the attitude. ${ }^{18}$ For example, one could postulate that the opposite of approval would be equal to the tolerance of the opposite (i.e. $\sim \mathrm{A}(\mathrm{p})=\mathrm{T}(\sim \mathrm{p})$ ). The problem is that while it may be psychologically plausible, there is no way to ground the inconsistency between $\mathrm{A}$ and $\mathrm{T}$ in the logical system. Our theory captures the (n2) negation internally by postulating further quantificational structure, and thus avoids the need to postulate any new attitudes. In fact, our theory gives a logical, expressivist account of exactly what tolerance amounts to - namely approval for some arrangement of desires. Thus, tolerance of an activity is not withholding of approval (or disapproval) but rather approval under special circumstances (e.g. the evaluated agent wants to do it). ${ }^{19}$

\footnotetext{
${ }^{17}$ It is important to note that this duality is not merely postulated but logically inherited from the quantifiers.

${ }^{18}$ See section 1.

${ }^{19}$ We have analyzed the moral domain (the required, permitted, and forbidden) in terms of a primitive (non-moral) act of approval and quantification over sets of desires. This might seem to go against the intuition that permissibility is simply the lack of approval or disapproval. To test our intuitions here, consider a b-case where an action, like wearing heels, is neither
} 
Third, our theory provides a sufficiently general solution that explains the problem of embedding for conjunction. Recall that the expressivist appears to run out of slots when trying to account for (n2) below:

$\left(\mathrm{S}_{\&}\right)$ Sally thinks giving to charity is required.

(\&1) Sally thinks giving to charity is required and Sally thinks paying higher taxes is required.

(\&2) Sally thinks giving to charity is required and paying higher taxes is required.

(\&3) Sally thinks giving to charity and paying higher taxes is required.

On our analysis, the additional quantificational structure allows for the following solution in accounting for all three conjunctions of S:

$\left(\mathrm{S}_{\&}{ }^{* *}\right) \mathrm{A} \square$ (giving to charity)

$\left(\& 1^{* *}\right) \mathrm{A} \square$ (giving to charity) \& A $\square$ (paying higher taxes)

$\left(\& 2^{* *}\right) \mathrm{A}[\square$ (giving to charity) \& $\square$ (paying higher taxes)]

$\left(\& 3^{* *}\right) \mathrm{A} \square[$ (giving to charity) \& (paying higher taxes)]

In $\left(\& 1^{* *}\right)$, there are two separate acts of unconditional approval. In $\left(\& 2^{* *}\right)$, there is a single act of approval for two activities, each unconditionally. And in $\left(\& 3^{* *}\right)$, there is a single act of unconditional approval of a conjunctive activity.

Finally, the new notation clearly demonstrates how our view successfully tracks traditional normative distinctions:

(L1) $\mathrm{A} \square(\mathrm{p})=\mathrm{p}$ is required $(\mathrm{S})$.

(L2) $\mathrm{A}^{\sim} \square(\mathrm{p})=\mathrm{A} \nabla^{\sim}(\mathrm{p})=\sim \mathrm{p}$ is permitted (n2).

(L3) $A \square(\sim p)=p$ is forbidden (n3).

(L4) $\mathrm{A}^{\sim} \square(\sim \mathrm{p})=\mathrm{p}$ is permitted [or $\left.\mathrm{A} \diamond(\mathrm{p})\right]$.

(L1-L4) preserve all of the traditional inferential, normative relations:

(L1) [p is required] is inconsistent with (L2) [ $\sim \mathrm{p}$ is permitted].

(L1) [p is required] is inconsistent with (L3) [p is forbidden].

(L3) [p is forbidden] is inconsistent with (L4) [p is permitted].

forbidden nor required. Our view entails that in such a case if George wants to wear heels, we approve of him doing so. And if George wants not to wear heels, we approve of him not doing so. Denying approval to George in either case is tantamount to either thinking that wearing (or not wearing) heels is impermissible (n3), or else being agnostic regarding George's wearing heels. Clearly the first result is unacceptable. The second result, where someone might truly be agnostic, is also unacceptable since to be undecided about whether wearing heels is forbidden, permitted or required, is not the same thing as being decided that wearing heels is permitted. We take this to show that the initial intuition that permissibility is simply the lack of approval or disapproval conflates agnosticism with permissibility. 
(L1) [p is required] is consistent with (L4) [p is permitted].

(L2) [ $\sim \mathrm{p}$ is permitted] is consistent with (L3) [p is forbidden].

(L2) [ $\sim \mathrm{p}$ is permitted] is consistent with (L4) [p is permitted].

\section{Expressivism without the Negation Problem}

We have argued that 'required', 'permitted', and 'forbidden' can be analyzed in terms of quantification and a primitive two-valued normative attitude. We have said little, however, about this primitive normative attitude nor have we explained our insistence that the attitude be two-valued. Part of the reason for this is that we have not wanted our account to depend upon the details of our choice of a normative attitude. Whether the primitive normative attitude is approving, hooraying, being for, or commending, the semantic contents of moral terms like 'required', 'forbidden', and 'permitted' can be built up by quantification over the object of these primitive attitudes.

But suppose a defender of the Negation Problem concedes this argument but raises worries about our primitive normative attitude. Such a critic might argue that the Negation Problem will arise for any normative attitude, including our primitive normative attitude. Or, if we stipulate that our primitive attitude is two-valued, she might doubt whether there are any two-valued normative predicates. From this point of view, we have not solved the problem - we have merely shifted it onto something else. ${ }^{20}$

Notice however that this critic has struck out into new territory. Unwin showed that the Negation Problem arises for 'required', 'forbidden', and 'permissible' which are clearly three-valued; he gave no arguments that a similar problem would always arise for any normative predicate or that all normative predicates are three-valued. Let us call the view that all normative predicates have a negation problem because there are no two-valued normative predicates, the New Negation Problem. This critic would be right to point out that we have, thus far, given no arguments against this New Negation Problem. However, there have also been no arguments in favor of the New Negation Problem. Whether there is a two-valued normative primitive or not is simply not a question that Unwin or anyone else has discussed. At the very least, therefore, by showing that 'required', 'permissible', and 'forbidden' can be semantically decomposed into quantification and a normative primitive, we have shifted the debate from the Negation Problem to the New Negation Problem.

Furthermore, a defender of the New Negation Problem assumes that any normative primitive must be expressed in language. If we fail to produce a term in English that plays this function, a perfectly natural thing to say is that 'required', 'permissible', and 'forbidden' are linguistically primitive, but nevertheless have structure that is not overtly expressed in the language. Our account

\footnotetext{
${ }^{20}$ Thanks to Mark Schroeder for bringing these concerns to our attention. Much of this section has been recast to reflect these concerns.
} 
gives an expressivist answer to the Negation Problem in terms of quantification over the objects of such an unexpressed linguistic primitive.

Finally, and most decisively, we believe that the New Negation Problem can be resolved because there are such normative primitives in English. In The Language of Morals, Hare claims that the primary sense of 'good' is 'the most general adjective of commendation" (Hare 1958: 148). In fact, Hare argues that value words are tied directly or indirectly to situations of choice (Hare 1958: 128) where the speaker means to commend one of the alternatives. Thus, a good painting is one that we commend as being worth seeing, studying, or buying (Hare 1958: 128), and there is no such thing as a good wireworm because we never have an occasion to choose between wireworms (Hare 1958: 127). Commending is two-valued. I can commend doing X or not doing X, but I cannot commend neither doing $\mathrm{X}$ nor not doing $\mathrm{X}$. It follows that if Hare is right then all value words are two-valued.

But for our purposes, we do not have to agree with this strong thesis. We do not need 'good', let alone all value words, to always express commendation, we just need for it to be the case that 'good' sometimes has a commendatory meaning. Even the 'sometimes' claim would be quite a blow for friends of the New Negation Problem. We have seen that they are committed to holding that there are no two-valued normative predicates, and here we have picked out a sense of a perfectly ordinary one that is indeed two-valued.

Let us try to stipulate a situation in which 'good' is used in this way. According to defenders of the New Negation Problem, attempts to stipulate such a situation should fail. Any context for the word 'good' will always yield an instance of the Negation Problem. Suppose a friend and I are in a debate over basketball greatness. After much wrangling on a standard, we decide that $\mathrm{X}$ is better than $\mathrm{Y}$ if and only if you would commend drafting $\mathrm{X}$ before $\mathrm{Y}$. Now notice that we have an attributive adjective that has been tied directly to a situation of choice and thus conforms to Hare's understanding of a value word. At the top of my list, I place Michael Jordan and then move on down. Now suppose that I come to Magic and place him in front of Bird. My friend hesitates because she disagrees. Aren't there three ways in which she can disagree with me? Letting $\mathrm{S}$ stand for the agreement case, we seem to have the following three familiar options:

$\left(\mathrm{S}_{9}\right)$ Sally thinks Magic is better than Bird.

$\left(\mathrm{n} 1_{9}\right)$ It is not the case that Sally thinks Magic is better than Bird.

(n29) Sally thinks Magic is not better than Bird.

$\left(n 3_{9}\right)$ Sally thinks Magic is worse than Bird.

Interpreting 'good' as commending seems, again, to leave us without enough structure:

( $\left.\mathrm{S}^{\prime}\right)$ Sally commends drafting Magic over Bird.

$\left(\mathrm{n} 1_{9}{ }^{\prime}\right)$ It is not the case that Sally commends drafting Magic over Bird. 
$\left(\mathrm{n} 29^{\prime}\right) ? ? ? ?$

$\left(\mathrm{n} 3_{9}{ }^{\prime}\right)$ Sally commends drafting Bird over Magic.

The problem with capturing $\left(\mathrm{n} 2_{9}\right)$ is that it seems to allow for two different possibilities: (option c) Sally could believe that Bird is better than Magic or (option b) Sally could believe that neither Magic is better than Bird nor is Bird better than Magic. (c) is captured by (n39) and has a straightforward expressivist analysis - Sally commends drafting Bird over Magic. (b) is more problematic and seems to lack a commendatory translation. There is simply no way to commend neither picking Magic over Bird nor Bird over Magic. If commendation is meant to be followed, such a commendation would leave us with nothing to do. So perhaps, despite our best efforts, (b) type cases are always possible, and the New Negation Problem is vindicated.

However, we believe that appearances are misleading in such action-guiding cases and that, on closer analysis, (b) type cases are captured by (n19). Notice first of all that in an actual situation where I was getting advice on how to draft, I would be somewhat puzzled by my consultant's saying that neither Bird was better than Magic nor was Magic better than Bird. I am puzzled because after hearing this I still have to draft someone, and I don't know what to do. Perhaps, Sally believes that there is not a big enough difference between the two that she could recommend one over the other. She could claim that choosing between Magic and Bird was like choosing between two identical bales of hay - there are no grounds to commend one over the other. The decision between Magic and Bird cannot be made based on reasons. One must simply decide like Buridan's Ass had to decide. But if this is what (b) looks like, then one way to describe Sally's attitude is to say that she thinks commending is inappropriate in this case. Sally thinks neither is better nor worse than the other because better and worse don't apply here. With regard to better and worse, Sally doesn't think anything at all. If all this is correct, then (b) type cases are really just instances of $\left(\mathrm{n} 1_{9}\right)$, and $\left(\mathrm{n} 2_{9}\right)$ can be safely captured by saying that Sally either believes that Bird is better than Magic (n39), or doesn't have better or worse beliefs with regard to Bird and Magic at all $\left(n 1_{9}\right)$. In such action-oriented circumstances, we conclude that the New Negation Problem does not arise.

Finally, observe that our normative primitive still faces the embedding problem. When I say that if Jordan is better than Wilt, then so is Magic, it is still unclear how the expressive meaning of the term can remain the same in unasserted contexts. A consequence of this argument, therefore, is that the Negation Problem is not the same as the original embedding problem. While embedding besets all normative language, two-valued or otherwise - Unwin's problem only besets those terms for which negating the affirmation does not equal affirming the contrary. The original embedding problem is simply not the same as the modern Negation Problem. 


\section{The Hidden-Quantification View vs. Schroeder's Being For-View}

In the previous sections, we have advanced a solution to the Negation Problem that 1) does not equate it with the embedding problem, 2) mirrors nonnormative cases of hidden quantificational modification, and 3) suggests a hidden quantification reading of the normative words 'required', 'permissible', and 'forbidden'. We have not, however, argued for the uniqueness, or even the superiority of our solution to other existing solutions to the Negation Problem. While we do not undertake this whole task in this paper, we would like to compare our solution to Mark Schroeder's attempt to solve the Negation Problem. We have chosen to focus on Schroeder's solution primarily because it is the most detailed attempt. However, focusing on Schroeder's account has the additional advantage that his account is a foil for our own. Firstly, it bears some superficial formal similarities to our view in that both accounts see the problem as one that derives from a lack of sufficient structure in traditional expressivist analyses. Secondly, comparing Schroeder's account to our own brings out, in contrast, an important feature of our approach. We have argued that the Negation Problem can be solved by adding quantificational structure to an existing expressivist solution of the embedding problem. Schroeder, however, suggests a more radical remedy. He believes that the Negation Problem cuts so deep that the very structure of an expressivist solution to the embedding problem must be revised.

Schroeder models his solution to the Negation Problem on the descriptive case. When Bob says that grass is green, we don't understand him by combining the 'thinks' and 'green' into one thinks-green attitude that is borne to the content of the subject term 'grass'. Instead, we break the thinks-green attitude into a more general attitude of believing that is borne to greenness of grass (Schroeder 2008b: 56-57, 2008a: 588-589). So, too, argues Schroeder we need to break thinks-required up into a general attitude that is borne to the requirement of charity. On this view, the only place in which expressivists depart from descriptivists is in thinking that the general attitude that is borne to the content of the predicate 'required' is not a cognitive attitude. The name that Schroeder picks out for this general non-cognitive attitude that can be borne to the contents of normative predicates is being for. According to Schroeder's theory, then, expressivists do not disagree with descriptivists in thinking that 'wrong' and other normative terms are predicates - instead they disagree only in thinking that the proper attitude toward the contents of these normative predicates is a cognitive one.

Of course, it remains to find appropriate descriptive predicates for all the normative terms. But Schroeder does not want to get hung up on details here. He suggests that 'wrong' corresponds to the descriptive property of blaming for, and correspondingly, we might add that 'required' corresponds to the descriptive property of praising for (2008a: 589, 2008b: 58, 2012: 736). ${ }^{21}$ The phrase

\footnotetext{
${ }^{21}$ To be perfectly clear, we are not introducing two separate psychological states: praising for
} 
'charity is required' contains a two-place predicate (praising for) which has the speaker of the sentence as one of its subjects and giving to charity as the other. When Sally thinks that charity is required she has the non-cognitive attitude of being for the contents of this two-place predicate, and when she says 'charity is required' she expresses this non-cognitive attitude. It is important to note that ordinary normative judgments about some activity always correspond to a being for of some relation to that activity. It is thus impossible to simply be for giving to charity, just as it is impossible to simply believe grass. ${ }^{22}$ Whenever 'giving to charity' occurs in some normative sentence the speaker will be for the contents of some predicate that has giving to charity as one of its subjects, but the speaker will never simply be for giving to charity. Finally, it should be observed how far we have come from traditional non-cognitivists like Ayer 1936 who claimed that the essential difference between evaluative and other terms is that the former, unlike the latter, contributed nothing to the "factual content" of the sentence. On Schroeder's view 'wrong' and 'required' function much like 'green' and 'rectangular,' the distinctively expressivist part comes in what it means to think something required versus what it means to think something green (Schroeder 2012: 736$).^{23}$

The pay-off of this view in terms of the Negation Problem is immediate. Schroeder offers the following analysis of $\mathrm{S}$ and its negations. ${ }^{24}$

\begin{tabular}{|l|l|l|}
\hline $\begin{array}{l}\text { (S) Sally thinks giving to charity } \\
\text { is required. }\end{array}$ & $\rightarrow$ & $\begin{array}{l}(\mathrm{S} \wedge) \text { Sally is FOR(praising for } \\
\text { giving to charity). }\end{array}$ \\
\hline \hline $\begin{array}{l}\text { (n1) Sally doesn't think giving to } \\
\text { charity is required. }\end{array}$ & $\rightarrow$ & $\begin{array}{l}\left(\mathrm{n} 1^{\wedge}\right) \text { Sally is not For(praising } \\
\text { for giving to charity). }\end{array}$ \\
\hline \hline $\begin{array}{l}\text { (n2) Sally thinks that giving to } \\
\text { charity is not required. }\end{array}$ & $\rightarrow$ & $\begin{array}{l}\left(\mathrm{n} 2^{\wedge}\right) \text { Sally is FoR(not praising } \\
\text { for giving to charity). }\end{array}$ \\
\hline \hline $\begin{array}{l}\text { (n3) Sally thinks not giving to } \\
\text { charity is required. }\end{array}$ & $\rightarrow$ & $\begin{array}{l}\left(\mathrm{n} 3^{\wedge}\right) \text { Sally is FoR(praising for } \\
\text { not giving to charity). }\end{array}$ \\
\hline
\end{tabular}

Now Schroeder insists that it is the structure of his solution not his specific choices of being for and blaming for that are important, ${ }^{25}$ but we think that important structural features of Schroeder's account are revealed by some attention to these choices. When defining 'being for' Schroeder notes that it is a "very general positive attitude... and we can add that if someone is for something, then they will tend to do it, other things being equal" (2008a: 589). In other words, being for is motivating. As a consequence of the motivating

and blaming for. The introduction of the term 'praising for' is a mere notational convenience and could be replaced throughout with 'blaming for not'.

${ }^{22}$ This is the mistake that Schroeder attributes to Skorupski 2012 in his interpretation of Schroeder 2008b. See Schroeder 2012: 737.

${ }^{23}$ As Schroeder puts it, "The 'being for' part comes not from the compositional semantics at all, but from the accompanying account of what it is to believe one of these properties" (Schroeder 2012: 736).

${ }^{24}$ See Schroeder 2008b: 73. The small caps denote mental states. (Schroeder 2008b: 58)

${ }^{25}$ Schroeder 2008b: 58, 2008a: 589 . 
character of being for, it follows that the object of this attitude must be an action since only an action could be the proper object of a motivating attitude. ${ }^{26}$ What's more since I can't be motivated to perform an action of yours, it also follows that the object of the attitude being for is one of the speaker's actions. Thus, if Sally is for praising for giving to charity, she has a reasons-providing attitude toward the action of: Sally praising giving to charity. This is a good result for Schroeder because many expressivists have accepted the internalism requirement (IR) which says precisely that if an agent accepts a moral claim, then she is motivated to do it. So if $(S)$ is motivating and $(S \wedge)$ professes to provide the meaning of $(S)$, then $(S \wedge)$ better be motivating too.

Unfortunately, however, $(\mathrm{S})$ and $(\mathrm{S} \wedge)$ motivate different things. According to Schroeder being for provides you with a motive to do the thing you are for, in this case, it provides Sally a motive to praise giving to charity. But (S) gives Sally a motive to give to charity. Surely, these two things can come apart. One can give to charity without praising giving to charity, and praise it without actually giving to it. Nor need this involve any sort of irrationality. Many consequentialists have argued that we have reason to praise what we have no reason to do and reason to do what we have no reason to praise. ${ }^{27}$

It is important to see that this point does not depend upon Schroeder's particular decisions regarding being for or blaming for. At one point, Schroeder suggests that 'blaming for' could be replaced with 'avoiding' (2008a: 589, 2008b: 74 ) or 'disapproving'(2008b: 58). Sticking with our policy of switching negative attitudes with affirmative opposites, we take this suggestion to mean that 'praising for' could be replaced with 'seeking' or 'approving'. (S) would then translate to

$\left(\mathrm{S}^{\wedge}\right)$ Sally is FOR(seeking to give to charity).

$\left(\mathrm{S}^{\wedge}{ }^{\prime \prime}\right)$ Sally is FOR(approving of giving to charity).

Notice, however, that the very same issue arises for these two suggestions. Whereas (S) gives Sally reason to give to charity, according to Schroeder's own definition of 'being for', $\left(\mathrm{S}^{\wedge}{ }^{\prime}\right)$ only gives her reason to seek out giving to charity, and $\left(\mathrm{S}^{\prime \prime}\right)$ only gives her reason to approve of giving to charity. But again these activities are different. And, of course, if two actions are different then their consequences could be different, and a consequentialist would think that Sally could have reasons for one but not the other.

At this point Schroeder has a few options. He can deny IR by denying that (S) really motivates Sally to give to charity. This is an unattractive option. One of the traditional advantages of expressivism over their non-expressivist

\footnotetext{
${ }^{26}$ Thus, Sinclair's summary of Schroeder's being for as an ascended attitude must be mistaken. While I can have an attitude toward another attitude, I can't have a motivating attitude toward another attitude. Perhaps, I could have a motivating attitude toward adopting an attitude or continuing to hold an attitude, but I can't have a motivating reason to an attitude. Thus, when Sinclair says that ' $x$ is M' expresses $\alpha ! \beta ! x$ (Sinclair 2011: 390), we don't understand the second '!'.

${ }^{27}$ Sidgwick 1907: 428, for example, claims that about the supererogatory. Sinclair 2011 makes a similar point (409-410), see also Horgan and Timmons 2009: 106.
} 
counterparts is that it has a compelling story on how accepting a moral claim can be motivating - it is motivating because someone who expresses such a claim has a positive attitude toward the activity they claim is required. ${ }^{28}$ To abandon this would be to abandon one of the central reasons to be an expressivist in the first place.

But if Schroeder accepts IR, then Sally thinking that charity is required actually gives her reason for two different things. First, since $(S \wedge)$ gives the meaning of (S), she has reason to praise for giving to charity, and second, since (S) is itself motivating (by IR) she also has reason to give to charity. Setting aside the consequentialist objections adverted to above, this is not an implausible position. It might very well be a fact about the psychological state of praising for $\mathrm{X}$ that having reason to praise for $\mathrm{X}$ necessitates having reason to $\mathrm{X}$ itself. ${ }^{29}$ This solution, however, incurs an explanatory debt. How is it that praising for $\mathrm{X}$ transmits reasons toward its intended subject such that having reason to praise for $\mathrm{X}$ entails having a reason to $\mathrm{X}$ ? This is certainly not true of most predicates that have activities as subjects. For example, reasons to deliberate about whether to give to charity do not also provide reasons to give to charity. It follows that it must be a specific feature of praising for that it transmits reasons to the activity that is its subject. What's more this explanatory debt multiplies. Since Schroeder thinks that every normative word has its own descriptive predicate, he must explain how each of these descriptive predicates has the reasons transmitting property.

This difficulty doesn't beset traditional expressivism. If the expressivist attitude is directed immediately toward the activity itself, then the reason why an agent who accepts (S) has reason to give to charity is explained directly by the attitude that is invoked in the expressivist analysis. By interposing an extra descriptive predicate between the attitude and the activity toward which the attitude is directed, Schroeder has obscured this relationship. It is no longer a feature of the expressivist analysis itself that accepting a normative sentence about an activity gives one reason to do the activity. Instead it has to do with the reasons transmitting features of the descriptive predicates themselves.

A chief advantage of the quantificational view is that it wears its explanation for IR on its sleeve, i.e. IR is explicitly part of the analysis. Recall our analysis:

\begin{tabular}{|l|l|l|}
\hline $\begin{array}{l}\text { (S) Sally thinks giving to charity } \\
\text { is required. }\end{array}$ & $\rightarrow$ & $\begin{array}{l}\left.\text { ( } \mathrm{S}^{\prime}\right) \text { Sally approves of giving to } \\
\text { charity unconditionally. }\end{array}$ \\
\hline
\end{tabular}

Since approving of something unconditionally involves approving of it for all sets of desires, explaining the internalism requirement for $S^{\prime}$ is no more mysterious than explaining why having reason to walk everyday gives you reason to walk. Schroeder was right to insist on additional structure, but the internalism requirement demands that this structure not interfere with the expressive element's ability to provide a reason to do the action. The quantificational view

\footnotetext{
${ }^{28}$ See, for example, Smith 1994: 11-12.

${ }^{29}$ Thanks to Dustin Tucker for pointing this possibility out to us.
} 
reflects this demand by analyzing 'thinks required' as a kind of approval. In fact, reflecting on the internalism requirement and the need for more structure, the quantificational view only seems natural.

\section{Conclusion}

Previous understandings of the Negation Problem have tended to see it either as a special case of the embedding problem that arises as an interaction of expressivism with features of negation or, more generally, as a problem that faces expressivism whenever it tries to explain any embedded logical operator. The solutions to the Negation Problem have usually involved changes to expressivism itself. If we are right, however, the Negation Problem for expressivists doesn't have anything to do with expressivism or negation, but arises because of hidden structure within the usual examples in expressivist literature. Accordingly, our solution consists in making this hidden structure explicit. We suggest that normative words like 'required', 'permissible', and 'forbidden' can be understood as a kind of quantificational normative approval. This solution to the Negation Problem has three distinct advantages over existing solutions. One, since the Concentric Structure for Negation occurs in non-expressive language where it is resolved through hidden quantification, this solution is grounded more generally in the semantics of natural language. Two, the quantificational account does not demand wholesale changes of expressivism in the face of the Negation Problem. Three, the quantificational account has a ready explanation for why motivation transmits through its structure since the structure that we have added modifies the predicate. ${ }^{30}$

\section{References}

[1] Attfield, Robin. "Supererogation and Double Standards." Mind 88.1 (1979): 481-499.

[2] Ayer, Alfred Jules. "Language, Truth and Logic (1936)." Victor Gollancz, London (1946).

[3] Baron, Marcia. "Kantian Ethics and Supererogation." The Journal of Philosophy 84.5 (1987): 237-262.

[4] Blackburn, Simon. Spreading the Word. Oxford: Clarendon Press, 1984.

[5] —. "Attitudes and Contents." Ethics 98.3 (1988): 501-517.

[6] —. Ruling Passions. Oxford: Clarendon Press, 1998.

\footnotetext{
${ }^{30}$ Thanks to Jacob Beck, Mark Schroeder, Dustin Tucker, and audiences at Northwestern University and Texas Tech University for their helpful feedback. This work was made possible, in part, through the generous support of the Stanford Humanities Center.
} 
[7] Davidson, Donald. "The Logical Form of Action Sentences." Essays on Actions and Events 5 (1967): 105-148.

[8] Dreier, Jamie. "Disagreeing (about) What to Do: Negation and Completeness in Gibbard's Norm-Expressivism*." Philosophy and Phenomenological Research 72.3 (2006): 714-721.

[9] Geach, Peter T. "Assertion." The Philosophical Review 74.4 (1965): 449465.

[10] Gibbard, Allan. Thinking How to Live. Harvard University Press, 2003.

[11] Hare, Richard Mervyn. The Language of Morals. Oxford University Press, 1952.

[12] —. "Meaning and Speech Acts." The Philosophical Review 79.1 (1970): $3-24$.

[13] Horgan, Terry, and Mark Timmons. "Expressivism and Contrary-Forming Negation." Philosophical Issues 19.1 (2009): 92-112.

[14] King, Jeffrey C. Complex Demonstratives: A Quantificational Account. Vol. 2. MIT Press, 2001.

[15] Köhler, Sebastian. "The Frege-Geach Objection to Expressivism: Structurally Answered." Journal of Ethics 83 Social Philosophy, discussion note (2012).

[16] Kratzer, Angelika. "Modality." Semantics: An International Handbook of Contemporary Research. Eds. Arnim von Stechow and Dieter Wunderlich. Berlin: W. de Gruyter, 1991. 639-50.

[17] Plato. The Republic. tr. and ed. Allan Bloom. The Republic of Plato. Basic Books, 1991.

[18] Pybus, Elizabeth M. "'Saints and Heroes'." Philosophy 57.220 (1982): 193199.

[19] —. "A Plea for the Supererogatory: A Reply." Philosophy 61.238 (1986): 526-531.

[20] Raz, Joseph. "Permissions and Supererogation." American Philosophical Quarterly 12.2 (1975): 161-168.

[21] Russell, Bertrand. "On Denoting." Mind 14.56 (1905): 479-493.

[22] —. "Descriptions." Introduction to Mathematical Philosophy (1919): 16780.

[23] Schroeder, Mark. "How Expressivists Can and Should Solve Their Problem with Negation." Noûs 42.4 (2008a): 573-599. 
[24] —. Being For: Evaluating the Semantic Program of Expressivism. Oxford University Press, 2008b.

[25] —. "Skorupski on being for." Analysis 72.4 (2012): 735-739.

[26] Sidgwick, Henry. The Methods of Ethics. Hackett Publishing, 1907.

[27] Sinclair, Neil. "Moral Expressivism and Sentential Negation." Philosophical Studies 152.3 (2011): 385-411.

[28] Skorupski, John. "The Frege-Geach Objection to Expressivism: Still Unanswered." Analysis 72.1 (2012): 9-18.

[29] Smith, Michael. The Moral Problem. Oxford: Blackwell, 1994.

[30] - Ethics and the a priori: Selected Essays on Moral Psychology and MetaEthics. Cambridge University Press, 2004.

[31] Thomason, Richmond H., and Robert C. Stalnaker. "A Semantic Theory of Adverbs." Linguistic Inquiry 4.2 (1973): 195-220.

[32] Unwin, Nicholas. "Quasi-Realism, Negation and the Frege-Geach Problem." The Philosophical Quarterly 49.196 (1999): 337-352.

[33] —. "Norms and Negation: A Problem for Gibbard's logic." The Philosophical Quarterly 51.202 (2001): 60-75.

[34] Urmson, James O. "Saints and Heroes." Essays in Moral Philosophy (1958): 198-216.

[35] Wedgwood, Ralph. "Schroeder on Expressivism: For-or Against?." Analysis 70.1 (2010): 117-129. 